\section{Effects of Discrimination of Expectant Ladies on the Economic Performance of Private Firms within the Kenyan Context}

\author{
Jaffer Fatma Ahmed. \\ Jomo Kenyatta University of Agriculture and Technology. \\ Department of Human Resource Management \\ E-mail: fatma_jaffer@yahoo.com
}

Doi:10.5296/ijhrs.v4i1.5709

URL: http://dx.doi.org/10.5296/ijhrs.v4i1.5709

\begin{abstract}
.
Gender discrimination is currently highly affecting the economic performance of Indian-owned private firms within the Kenyan context. This form of discrimination is particularly featuring expectant ladies who are already working or are currently trying to gain access into the work environment within private organizations. This kind of discrimination has not only affected the expectant ladies, but it has also hindered economic development within the firms that allow this practice to continue.
\end{abstract}

This is evident by the ladies' careers being halted because they are expectant and hence considered unable to deliver towards the organizations' objectives. On the other hand, the organization ends up losing valuable employees who would have played a major role in the growth of such firms. Moreover, when some of the ladies discriminated against are bold enough to go to court, the firm losses a lot of money and their identity in the business world is also tarnished, as they have to compensate the lady who is the victim.

Discrimination of ladies on the basis of being expectant has been quietly endured by the victims involved, silently suffering; with very few trying to ensure their rights are protected, as per the Kenyan constitution, under the Employment Act, 2007.

Data will be collected using questionnaires, interviews and through research done earlier on Gender discrimination. Research will also involve statistical data that has been analyzed on gender discrimination and review of how the practice is affecting our society over the years.

\section{KEYWORDS}

Constitution, Employment Act, discrimination, expectant ladies

1.0 INTRODUCTION.

In Kenya, gender discrimination on expectant ladies has been highly practiced within private 
organizations, without being addressed in public. Despite women being protected by the constitution concerning this issue, the Employment Act, 2007, has not been given due significance as expected.

Indeed, research has shown that the ways that men and women are treated differently in the workplace can be nearly imperceptible at the level of the individual and emerge only when aggregated across individuals (Welle and Heilman, 2005). Crosby (1984), for example, demonstrated that by and large, women do not acknowledge the ways that gender discrimination may have affected their own career experiences. They are more likely toassume personal responsibility for receiving fewer organizational resources than their male coworkers. These same women, however, believe that gender discrimination exists in the workplace and affects the resources that other women receive.

It is no exaggeration to say that one of the main components of national success is the inclusion and utilization of highly skilled labor in the production process. One of the most reliable ways to ensure high levels of income and to raise resource efficiency is to increase human resource efficiency. Human resources are characterized not only by education, but also by gender dimensions. In this regard, women's economic contributions are vital and the ability to realize the full labor potential of women in the national economy is decisive to meet the challenge of attracting highly qualified employees to compete in international markets. Unfortunately, few nations and companies recognize the significance and potential that women hold (Sepashvili, 2012).

According to Mulenkei(2002), women's rights and the discrimination against them that limits the scope of their rights in most countries is not an accident. The causes of women's subordinationand unequal gender relations are deeply rooted in history, religions, culture, legal systems, political institutions and social attitudes.

The major problems to be highlighted are the various adverse effects of gender discrimination on female employees and the organization at large. Expectant ladies are still being seen as liabilities and hindrance to growth in private firms, yet they are still capable of working and contributing to the tremendous growth of the organization.

\subsection{PROBLEM STATEMENT.}

The purpose of this study is to highlight the high form of discrimination that many expectant ladies face while at the workplace or with regards to getting employment. This is especially the case with Indian private firms, and most ladies bear the discrimination quietly, hence the practice continues without any legal action.

According to Aidi (2012), Employers withhold maternity leave pay for women employees in Kenya's flower farms hence women suffer subtle discrimination in multi-million shilling industry. 
"With the economic crisis, there has been an increase of discrimination complaints. Pregnant women are particularly vulnerable. They tend to suffer from discrimination at work because of the idea that maternity is a liability, but the fact is that maternity protection produces enormous benefits." (Laura Addati, the ILO’s Maternity Specialist).

The objective of conducting this study is to highlight this vice that is depriving many ladies of an opportunity to pursue their careers. Pregnancy is a blessing that does not make a lady unable to perform her official duties, unless the pregnancy comes with complications, which is in special cases. It is with sincere optimism that with this study, discrimination of expectant ladies at the workplace will gain interest and be seriously looked into by Human Resource professionals who are to play the major role of ensuring the ladies' rights are considered and respected at all times.

This form of discrimination has been highlighted in the Kenyan constitution under the Employment Act, 2007, which states that "No employer shall discriminate directly or indirectly, against an employee or prospective employee or harass an employee or prospective employee

On grounds of ....sex...pregnancy...or HIV status”. Unfortunately, most Human Resource personnel still consider expectant ladies as a liability to an organization and hence do not protect their rights.

This is a section of the Kenyan constitution that protects employees and prospective employees from any kind of discrimination. However, this policy is not yet being practiced as per the expectations and hence resulting in breaching of the constitution which is the highest form of law in Kenya.

Stotsky (2006) posits that women's relative lack of opportunities in developing countries inhibits economic growth, while at the same time, economic growth leads to improvements in their disadvantaged conditions. Today, women are primary breadwinners in 40 percent of households with children, and three-quarters of women entering the workforce will become pregnant at least once while employed. Continued pregnancy discrimination jeopardizes families' financial stability and health at a critical time (Pew Research Centre, 2013).

"But it is not just about helping individuals. Maternity protection has a significant impact on development, and research shows that it is of benefit to employers as well as employees because it helps companies and organizations retain valuable staff. " (Laura Addati, the ILO's Maternity Specialist).

\subsection{OBJECTIVES.}

\subsection{General Objective.}

To determine the effect of gender discrimination on the economic performance of an organization. 
3.2 Specific objectives.

1. To figure out how poor productivity of employees affects the economic performance of a firm.

2. To identify how reduced employee motivation can affect the economic performance of a firm.

3. To find out the effect of a poor company identity on the economic performance of an organization.

\section{O THEORIES RELATED TO GENDER DISCRIMINATION.}

\subsection{Symbolic Interactionism.}

Herbert Blumer (1969), who coined the term "symbolic interactionism," set out three basic premises of the perspective. They include, Human beings act toward things on the basis of the meanings that the things have for them, the meaning of such things is derived from, or arises out of, the social interaction that one has with one's fellows and these meanings are handled in, and modified through, an interpretive process used by the person in dealing with the things he/she encounters.

Blumer, following Mead, claimed that people interact with each other by interpreting or defining each other's actions instead of merely reacting to each other's actions. Their 'response' is not made directly to the actions of one another but instead is based on the meaning which they attach to such actions. Thus, human interaction is mediated by the use of symbols, by interpretation, or by ascertaining the meaning of one another's actions (Blumer, 1962).

Symbolic interactionism is a social constructionist approach to understanding social life that focuses on how reality is constructed by active and creative actors through their interactions with others.

Herbert Blumer, a student and interpreter of Mead, coined the term "symbolic interactionism" and put forward an influential summary of the perspective: people act toward things based on the meaning those things have for them and these meanings are derived from social interaction and modified through interpretation.

Symbolic interactionist researchers investigate how people create meaning during social interaction, how they present and construct the self or identity, and how they define situations of co-presence with others. One of the perspective's central ideas is that people act as they do because of how they define the present situation.

Symbolic interactionism as a theory can be used to explain gender discrimination in the workplace. This is due to the image most employers have created on ladies capabilities to perform at work, especially when expectant. Due to the discrimination attached with expectant ladies, most employers are not willing to accept them in the workplace and if they do, they do not provide all the rights entitled to them.

Fellow employees also end up forming negative meanings towards expectant ladies at the 
workplace, leading to gender discrimination. Moreover, the victimized employees also gain a negative perception of the organization and the employers, and this hinders optimum productivity within the organizational setting, affecting the social relationships at work.

The victimized employees may decide to go to court to claim their rights in the workplace, and this affects the image and identity of the organization to the external world, since the outside world will see the negative picture of the firm's discrimination towards its employees.

\subsection{Rational Bias Theory.}

Susan et al (1998) have focused on the work place gender discrimination rational bias theory. According to this theory, decision makers may choose to discriminate if they believe that their superiors or others having power over their careers expect or prefer it. The findings of their research showed that businessmen discriminated women, and people at the top of the organization are most biased against women than people at the bottom. Their study has also confirmed that management support discrimination, though those discriminations were less than the findings of earlier research, reflecting increasing equal opportunity. It was also confirmed through their research that the discrimination is more because of external pressures than from internal.

According to rational bias theory, there are instances in which engaging in discrimination seems justified to an employee, even though he or she may be aware of regulations prohibiting bias and may personally prefer to treat others equally (Larwood \& Gattiker, 1985; Larwood et al., 1984). Employees in decision-making positions understand that they have to take into account the attitudes and preferences of other people, such as superiors and clients, in order to enhance and develop their own careers. It follows that decision makers may choose to discriminate if they believe their superiors or others having power over their careers expect or prefer it. Thus, an employee's display of "rational bias," in which discrimination may be viewed as both instrumental and intentional, is the result of perceiving external pressures from superiors or clients to discriminate.

The perceptions that business norms favor discrimination and that compliance with the norms is important to business success are two basic tenets of rational bias theory. If these components are not accepted by decision makers, then the decision makers are less likely to feel external pressures to discriminate (Larwood et al., 1988a, 1988b). This suggests preconditions for rational bias to be operative in producing gender discrimination in the workplace: business people are viewed as generally more accepting of one gender than the other - at least in the organizational functions being examined; and those making personnel decisions feel pressure toward deferring to the norms of business (Dexter, 1985; Larwood et al., 1988a; Szwajkowski et al., 1991).

The first precondition, referred to as the "preference norm," does not need to accurately represent the beliefs of those in business - rather, the perception that the preference norm may 
exist could be sufficient to make it of concern. The second precondition, referred to as "compliance instrumentality," suggests that managers anticipate consequences to their careers if they do not adhere to perceived business norms. Previous research has demonstrated both the actual existence of the perceived business norms and that they take priority over employees' own beliefs (Gealy, Larwood, \& Elliot, 1979; Larwood \& Gattiker, 1985).

For example, consulting-firm owners have reported that clients were less likely to accept women as consultants than men, the types of problems women were assigned to were limited, and women had more difficulty making contacts with clients and establishing rapport (Gealy et al., 1979). Although the women consultants were considered to be as qualified as the men, those in a position to hire them into the consulting firms blamed their discrimination on the preference of their clients rather than on their own beliefs. Similarly, Larwood and Gattiker's (1985) study on the attitudes of management consulting clients confirmed that clients did generally prefer to work with male consultants and believed they would obtain better advice from a male. Thus, gender was a "rational" consideration for consulting firms in selecting a consultant to work with a client.

Given these conditions, biased decision making may even occur when a decision maker lacks actual information, or when ambiguity exists, concerning the specific preferences of someone having the ability to influence his or her career, that is, the power holder. The power holder may actually oppose discrimination, but without this explicit information the decision maker must rely on the perceived business norms asserting that discrimination is preferred (Gealy et al., 1979; Larwood \& Gattiker, 1985; Lott, 1985; Wiley \& Eskilson, 1982).

In other words, rational bias theory suggests that the self-interested decision maker will likely act in a manner that enhances his or her own career position, or diminishes any threats to it. Thus, a decision maker's display of rational bias decision making is a reaction to external pressure from superiors and/or clients to discriminate - whether real or assumed. Larwood et al. (1984), proposed that rational bias might take place under a series of conditions related to issues such as task importance, social signals from the power holder, and insecurity about one's relationship with the person in the power position.

Prior studies (Larwood et al., 1988a, 1988b; Powell \& Butterfield, 1994; Szwajkowski and Larwood, 1991) have directly examined these conditions, generally finding that rational bias plays a role in or is consistent with both gender and racial discrimination. In addition, participants reported beliefs that discrimination is a workplace norm, and that client and customer biases are difficult to change.

In summary, a decision maker decides to discriminate on the basis of his own self-interest in order to enhance his career position, but this may have a negative effect on the economic performance of the firm, since the external world may not perceive the discrimination as a good act hence tarnishing the identity of the organization. Moreover, the employees end up feeling demoralized towards working for the organization, and this affects their level of productivity immensely, hindering them from reaching their full potential. 


\subsection{LITERATURE REVIEW}

\subsection{Employee's Productivity.}

Gender discrimination turns the employees emotionally brittle. Simple peace loving employees transform into paranoid and suspicious, fearful and angry individuals. Elimination of Gender Discrimination is crucial for the satisfaction and motivation, commitment and enthusiasm and less stress of the employees (Channar et al, 2011).

The human resource managers should be careful with hiring \& promotion of the employees and providing facilities to employees in order to avoid any gender discrimination because it has a direct relationship on employee productivity and which will reduce organizational productivity. The human resource managers should provide facilities and provision of goods according to the ratio of men and women and ensure promotion of employees on merit and seniority wise (Abbas, 2011). With lack of satisfaction and stress within the workplace, the work environment is not conducive for the employees and this may result in poor productivity of the employees since they will not be in the right attitude to give their best.

This has been backed up by the theory of symbolic interactionism, whereby meaning is attached to the perceptions an individual acquires during interaction. If the employee does not feel appreciated and accepted by the organization, the level of productivity and commitment will definitely be hampered with.

\subsection{Commitment and Motivation of employees.}

Habib (2000) has studied the effects of Brick Wall and Glass ceiling in publicadministration of Bangladesh. His analysis has shown that women are discriminated in civil services of Bangladesh from entry to the higher posts (Glass Ceiling). Social cultural factors are the principal stumbling blocks and build a wall for entry of woman into civil services. Their career path was hindered by the impediments of the systematic and attitudinal reasons. Government laws and regulations in this regard are proving ineffective. However, that discrimination was not for the women who came from upper-class. This disparate treatment against women had implications for their morale, motivation and performance. This shows that gender discrimination has an impact on the commitment and motivation of employees in an organization.

Rational Bias theory explains this, whereby, decision makers feel that women are not capable of performing as per the expected standards, and that the powerful people in the society, such as businessmen, feel women should not be given higher posts and good incentives in the workplace. If given, the decision makers will not be able to succeed in the competitive world with set standards.

\subsection{Company's identity.}

Organizations must accept the importance of female workers and realize the international 
scenario of women fair representation and quotas in hiring, and facilities in organizations, otherwise they will get defame and bad reputation in corporate sector of the world which will reduce international business cooperation and lose large number of business orders. The decline in number of business orders from all over the world will affect the profitability and survival of the organizations. Therefore, top management must avoid discriminatory practices in hiring, promotion, and facilities to the employees irrespective of what is his/her gender. Positive and loyal culture will build in the organization which will increase the productivity and profitability of the organization (Abbas, 2011). Company identity is a vital aspect to be protected and valued in the corporate world to ensure good relations with the corporate players. Company identity should therefore be excellent to enable prosperity of the organizations.

According to Suda, 2002, one of the first steps in gender mainstreaming is for the Government of Kenya to strengthen institutional capacity by setting up gender management systems, elevating the Women's Bureau to a higher structure than a mere unit within a Ministry with adequate resources, and establishing gender focal points. This approach aims to mainstream gender into national and sectorial policies, plans and programmes. The integration of gender issues in all national and sectorial policies, plans and programmes will not only increase capacity in gender training and gender management within organizations but also ensure that gender impact assessments and gender policy appraisals are conducted routinely to detect any harmful effects of policies and programmes on men and women.

Another important step in gender mainstreaming is to have senior management personnel who deal with policy formulation and resource allocation committed to the goal of gender equality.

\section{OMETHODOLOGY.}

Data has mostly been collected through research, hence dealing with second hand data. Moreover, data has been gathered via observation method and interviews have also been conducted to some of the victims of gender discrimination and the management itself.

Analysis of the data is through previous researches that have been done on the same issue of gender discrimination and its impact on the economic performance of the firm.

\subsection{CONCLUSION.}

The economic success of any organization is highly dependent on many factors, with among the major factors being the human capital within the company. It is therefore vital for the employees working for an organization to be well taken care of, for them to be able to completely give out their best and be committed towards meeting the objectives of the organization.

Gender discrimination is still a menace that has been hindering employees from meeting their full potential within the workplace due to feeling deprived of their basic rights. Indian-owned 
companies are still dominating in gender discrimination, regarding female gender as a liability to the company, especially when expectant. This has made working under their management very difficult and frustrating over the years, despite the availability of the Kenyan Constitution which is meant to protect the rights of these employees.

\subsection{RECOMMENDATIONS.}

Suda, 2002, has come up with recommendations on how to curb gender discrimination and ensure equality by advocating for workable gender systems and programs that will offer adequate training on gender issues. Policies formulated should also be constantly reviewed to gauge the progress and success in their implementation. This should be ensured in both private and public organizations, especially the private ones, to ensure the policies in the constitution are effectively implemented by all firms under close monitoring.

The institutional commitment to mainstreaming gender equality should also be reflected in the behavior and attitudes of the organization's senior management staff, starting from the highest possible level. This is where the leadership and the primary responsibility for gender mainstreaming reside although all levels of staff should have the capacity to mainstream gender as a collective institutional responsibility (Suda, 2002). Employers should be enlightened and encouraged on the benefits of gender equality to the organization, so that the wrong perspectives currently being adhered to can be replaced by positive attitudes towards growth of both the employees and the organization, and not exploiting the employees for the benefit and growth of the organization.

The management plays a major role in gender equality. Their attitude and commitment towards ensuring gender equality at the workplace is bound to trickle down to the staff at the other levels. Management should therefore be committed towards eradicating gender disparity within the workplace as much as possible.

\section{REFERENCES.}

1. E. Contran(1987).Casebook on Kenya Customary Law, Professional Books Ltd and Nairobi University Press.

2. Beryl Aidi (2014). Kenya Human Rights Commission, Kenya.

3. Kenya Law Organization, from http://www.kenyalaw.org

4. Arnold M. Rose (1969). Human Behavior and Social Process: An Interactionist Approach, Houghton-Mifflin. Reprinted in Blumer

5. Blumer, Herbert (1969). Symbolic Interactionism: Perspective and Method, Berkeley, University of California Press.

6. Plummer, Kenneth (1975). Sexual stigma: An interactionist account, London.

7. African Union (2010) 'List of countries which have signed, ratified/acceded to the Protocol to the African Charter on Human and Peoples' Rights on the Rights of Women in Africa' from

http://www.africaunion.org/root/au/Documents/Treaties/List/Protocol\%20on\%20the\% 20Rights\%20of\%20Women.pdf 
8. International LabourOrganization,(1996). From newsroom@ilo.org

9. Beryl Aidi (2012). Kenya Human Rights Commission, Kenya

10. Arnold M. Rose (1969).Human Behavior and Social Process: An Interactionist Approach, Houghton-Mifflin. Reprinted in Blumer.

11. Blumer, Herbert (1969). Symbolic Interactionism: Perspective and Method, Berkeley, University of California Press.

12. Plummer, Kenneth. (1975). Sexual stigma: An interactionist account. London.

13. Women's Bureau (1999). Kenya: The Role of Women in Economic Development, Government Printers, Nairobi.

14. Abagi, O.(1999). Gender Responsive Policy Analysis for Poverty Reducing Employment Strategies for Africa: From Theory to Practice. Nairobi, Kenya.

15. Anker, R. and Knowles, J. C. (1986). Sex Inequalities in Urban Employment in the Third World. Macmillan Press, London.

16. Beneria, L. and Bisnath, S. (1996) .Gender and Poverty: An Analysis for Action. Gender in Development Monograph Series No. 2, UNDP.

17. Brettell, C. B. and Sargent, C. F. (1993). Gender in cross-cultural Perspective. Englewood Cliffs, Prentice Hall, New Jersey.

18. Commonwealth Plan of Action (1995). The 1995 Commonwealth Plan of Action on Gender and Development. A commonwealth Vision for Women Towards the Year 2000. Common Wealth Secretariat. 